\title{
Influência do processamento do grão de milho na digestibilidade de rações e no desempenho de bezerros
}

\author{
Fernando Miranda de Vargas Junior ${ }^{1}$, Luis Maria Bonnecarrère Sanchez ${ }^{2}$, Francisco Stefano \\ Wechsler ${ }^{3}$, Waldmaryan Bianchini ${ }^{4}$, Marcus Vinicius Morais de Oliveira ${ }^{5}$
}

\footnotetext{
${ }^{1}$ Faculdade de Ciências Agrárias - Universidade Federal da Grande Dourados.

2 Departamento de Zootecnia - Universidade Federal de Santa Maria.

${ }^{3}$ Departamento de Produção e Exploração Animal - Universidade Estadual Paulista.

${ }^{4}$ Escola Superior de Agronomia de Paraguaçu Paulista.

${ }^{5}$ Unidade Universitária de Aquidauana - Universidade Estadual de Mato Grosso do Sul.
}

RESUMO - Objetivou-se avaliar a influência do processamento grão de milho (inteiro, tratado com uréia ou moído na forma de quirera) sobre a digestibilidade de rações e no desempenho de bezerros desmamados precocemente e mantidos em regime de confinamento. A dieta foi formulada com silagem de sorgo como volumoso, em uma relação volumoso:concentrado de 40:60, na matéria seca. A digestibilidade in vivo da matéria seca (MS), matéria orgânica, proteína bruta, extrato etéreo, fibra em detergente neutro, fibra em detergente ácido, celulose, energia bruta e amido, o pH das fezes e o consumo de MS foram efetuados em um ensaio com seis bezerros, castrados, com sete meses de idade. A influência das dietas no desempenho dos animais foi avaliada em ensaio com 15 bezerros não-castrados e idades semelhantes aos do ensaio de digestibilidade, com peso vivo inicial médio de $159 \mathrm{~kg}$. O processamento do grão de milho não influenciou as variáveis analisadas, exceto o $\mathrm{pH}$ das fezes, que apresentou valor mais baixo nos animais que receberam dieta contendo grão de milho moído.

Palavras-chave: $\mathrm{pH}$ das fezes, uréia

\section{Effects of corn grain processing on digestibility of diets and performance of calves}

\begin{abstract}
The effect of corn grain processing (whole, treated with urea, or crushed forms) on the digestibility of diets and performance in early weaned calves kept in feedlot was evaluated. The diet was formulated with silage sorghum as forage in 40:60 forage to concentrate ratio (\%DM). Digestibility of dry matter (DM), organic matter, crude protein, ether extract, neutral detergent fiber, acid detergent fiber, cellulose, gross energy and starch, fecal pH and DM intake were evaluated in an assay using six 7-mo castrated calves. Treatment effect on animal performance was evaluated in an assay using 15 non-castrated calves with ages similar to those of the digestibility assay, with initial $159 \mathrm{~kg}$ BW. The corn grain processing did not affect the evaluated characteristics, except for fecal $\mathrm{pH}$, that was lower in the animals fed diet with crushed corn grain.
\end{abstract}

Key Words: fecal $\mathrm{pH}$, urea

\section{Introdução}

O desempenho animal está diretamente relacionado ao consumo de nutrientes, que, sua vez, depende da natureza física e química dos alimentos e da digestibilidade da dieta (Waldo, 1973; Ferrell, 1993).

Altos níveis de produção animal geralmente estão associados a aumento na proporção de alimentos ricos em carboidratos solúveis. Esse aumento na proporção de carboidratos solúveis pode ocasionar diminuição do $\mathrm{pH}$ ruminal, redução da digestibilidade da fibra (Owens \&
Goetsch, 1993; Van Soest, 1994) e diminuição no consumo (Bengochea et al., 2005), logo, a melhoria no desempenho não é proporcional ao aumento do conteúdo de energia da dieta.

Existem diversos tipos de processamento - como os tratamentos mecânicos (descascamento, prensagem, moagem e laminação) e térmicos (calor seco: tostagem, micronização e estalação; e calor úmido: cozimento, dilatação, floculação e peletização) -, todavia, nem todos são acessíveis econômica e tecnologicamente ao produtor brasileiro.

O milho é a principal fonte de amido utilizada em dietas para ruminantes. No entanto, seu aproveitamento depende 
dos métodos de processamento a que é submetido (Theurer, 1986). O processamento do milho serve para expor os grânulos de amido à digestão (Beauchemin et al., 1994), formando fissuras, quebrando, ou expandindo o amido, por meio da eliminação da película externa do grão, o pericarpo, que constitui uma barreira física que dificulta o ataque microbiano e a ação das enzimas digestivas do animal (Kotarski et al., 1992).

Segundo Orskov (1990), em ruminantes de pequeno porte, como ovinos, caprinos e bovinos de até $150 \mathrm{~kg}$ de peso vivo, é vantajoso que os grãos sejam fornecidos inteiros, em razão da maior habilidade de mastigação. No entanto, em bovinos adultos, deve ser feito um tratamento mínimo para evitar que quantidade excessiva de grãos não digeridos seja eliminada nas fezes.

O tratamento do grão inteiro de milho com uréia pode ser uma alternativa, pois, nesta forma de processamento, a amônia liberada na hidrólise da uréia corrói o pericarpo do grão de milho, formando fissuras na película, o que facilita a fermentação microbiana e a ação das enzimas digestivas secretadas pelo animal (Orskov, 1986). Ao mesmo tempo, funciona como conservante (Bothast et al., 1972), evitando a necessidade de secagem do grão após a colheita.

Assim, avaliou-se a influência do tratamento com uréia e da granulometria do milho na digestibilidade de rações e no desempenho de bezerros.

\section{Material e Métodos}

O trabalho foi realizado no Setor de Nutrição Animal do Departamento de Zootecnia da Universidade Federal de Santa Maria, em Santa Maria, Rio Grande do Sul.

Efetuou-se um ensaio com seis bezerros leiteiros (um da raça Jersey e cinco da raça Holandesa), castrados, com 7 meses de idade e peso vivo médio de $179 \mathrm{~kg}$. Com esses animais, foram verificados os parâmetros de digestibilidade in vivo de matéria seca (MS), matéria orgânica (MO), proteína bruta $(\mathrm{PB})$, extrato etéreo (EE), fibra em detergente neutro (FDN), fibra em detergente ácido (FDA), celulose (CEL), energia (E) e amido (AM), o pH das fezes e o consumo de matéria seca.

No período pré-experimental, os animais foram tratados contra endo e ectoparasitas e alojados em um galpão de alvenaria com baias individuais próprias para determinação da digestibilidade, providas de bebedouros automáticos, comedouros e recipientes coletores de fezes.

Como tratamentos, avaliaram-se três formas de fornecimento do milho: grão de milho inteiro (GMI); grão de milho inteiro tratado com uréia (GMIU); e grão de milho moído na forma de quirera, com $2 \mathrm{~mm}$ de diâmetro (GMM). A granulometria (PGMM) e o diâmetro geométrico médio (DGM) do milho moído e o consumo de energia elétrica (ECEE), em kWhora/tonelada para moagem do grão foram determinados segundo metodologias descritas por Harris (1970), Zanotto et al. (1996) e Pozza et al. (2005), respectivamente.

Como volumoso, utilizou-se silagem de sorgo forrageiro (híbrido AG 2002) e ofertou-se dieta com relação volumoso:concentrado de 40:60 na matéria seca. O concentrado foi composto de farelo de soja, uréia, sal branco, calcário calcítico e milho nas três formas de utilização (Tabela 1).

As dietas continham níveis semelhantes de nitrogênio e energia e foram balanceadas segundo recomendações do NRC (1996). A diferença no teor de proteína bruta entre a dieta com grãos de milho tratado com uréia e aquelas com grãos de milho sem uréia foi ajustada com acréscimo de uréia no concentrado.

A moagem dos grãos de milho foi feita com moinho de martelo sem peneira. Os grãos de milho fornecidos inteiros tratados com uréia receberam uma solução de uréia diluída em água a $40 \%$, correspondente a $2 \%$ do total de matéria seca do milho a ser tratado. Para facilitar a aplicação e garantir perfeita homogeneização, os grãos foram misturados à solução de uréia em um misturador horizontal. Em seguida, foram cobertos com lona plástica para impedir a volatilização da amônia e armazenados por quatro semanas em um galpão de alvenaria.

A duração total do experimento foi de 63 dias, divididos em três períodos de 21 dias: 10 dias de adaptação dos animais às dietas, 4 de avaliação do consumo médio voluntário e 7 dias de coleta de amostras para determinação da digestibilidade.

Tabela 1 - Composição percentual das dietas experimentais, na matéria seca

\begin{tabular}{lccc}
\hline Ingrediente & \multicolumn{2}{c}{ Forma de fornecimento do milho ${ }^{1}$} \\
\cline { 2 - 4 } & GMI & GMIU & GMM \\
\hline Silagem sorgo & 40 & 40 & 40 \\
Grão milho & 40,6 & - & 40,6 \\
Grão milho inteiro & - & 41,2 & - \\
tratado com uréia & & & \\
Farelo soja & 17,6 & 17,6 & 17,6 \\
Uréia & 0,6 & - & 0,6 \\
Sal branco - NaCl & 0,6 & 0,6 & 0,6 \\
Calcárí calcítico & 0,6 & 0,6 & 0,6 \\
\hline
\end{tabular}

${ }^{1} \mathrm{GMI}=$ grão de milho inteiro; GMIU = grão de milho inteiro tratado com uréia $\mathrm{GMM}=$ grão de milho moído. 
A alimentação foi fornecida aos animais em duas refeições diárias, em porções eqüitativas, uma pela manhã e a outra à tarde. Durante os períodos de adaptação e de determinação do consumo, a alimentação foi fornecida à vontade permitindo-se sobras de $10 \%$. Todavia, para determinação da digestibilidade, a oferta de alimento foi restrita a $90 \%$ do consumo registrado anteriormente. A ingestão de água não foi medida e, durante todo o período experimental, os animais tiveram livre acesso aos bebedouros.

Foram coletadas diariamente e armazenadas em freezer as amostras da silagem e dos concentrados ofertados, das sobras existentes no cocho e das fezes. Posteriormente, no final de cada período, estas amostras foram descongeladas, homogeneizadas e uma subamostra foi retirada e seca em estufa de ventilação forçada a $65^{\circ} \mathrm{C}$ por 72 horas. Depois de secas, as amostras foram trituradas em moinho tipo Willey com peneira de $1 \mathrm{~mm}$ e armazenadas em recipientes de vidro para posterior realização das análises bromatológicas (Tabela 2). As análises foram determinadas com base nos procedimentos descritos para matéria seca total (MS), proteína bruta (PB) e extrato etéreo (EE), segundo AOAC (1984); energia bruta (EB), segundo Harris (1970); amido (AM), segundo Kozloski et al. (1999); fibra em detergente neutro (FDN), fibra em detergente ácido (FDA) e celulose (CEL), segundo Goering \& Van Soest (1970).

$\mathrm{O} \mathrm{pH}$ das fezes foi determinado nos cinco dias de coleta fecal. Para isso, uma amostra de $9 \mathrm{~g}$ de fezes foi diluída em $60 \mathrm{~mL}$ de água e, depois de 30 minutos, foi medido o $\mathrm{pH}$ utilizando-se potenciômetro digital.

A digestibilidade aparente dos nutrientes foi determinada pelo método direto, pela diferença do total consumido e do total eliminado nas fezes. Essa avaliação foi realizada no período do 15 ao $20^{\circ}$ dia e, no período do 16 ao $20^{\circ}$ dia, foram recolhidas, pesadas e amostradas as fezes produzidas. Esses dados foram usados no cálculo dos coeficientes de digestibilidade de matéria seca (MS), proteína bruta (PB), extrato etéreo (EE), energia bruta (EB), amido (AM), fibra em detergente neutro (FDN), fibra em detergente ácido (FDA) e celulose (CEL).

O delineamento experimental foi constituído de um quadrado latino $3 \times 3$ repetido duas vezes, de modo que as colunas representaram os animais (seis animais) e as linhas, os períodos (três períodos), perfazendo seis repetições por tratamento. Foram avaliados os efeitos do tratamento com uréia e da granulometria dos grãos sobre o consumo de MS, a digestibilidade e o $\mathrm{pH}$ das fezes pela análise de variância e pelo teste de comparação de médias (SAS, 1990).

A análise da influência do processamento do grão de milho no desempenho dos animais foi feita em um expe- rimento com 15 bezerros leiteiros, não-castrados, com padrão racial e idade semelhantes aos dos animais utilizados no experimento de digestibilidade, 3 da raça Jersey e 12 da raça Holandesa, com peso vivo médio inicial de $159 \mathrm{~kg}$.

Antes de iniciar o experimento, todos os animais foram tratados contra endo e ectoparasitas e alojados em piquetes individuais de $8 \mathrm{~m}^{2}$, parcialmente cobertos, contendo bebedouro e cocho. A duração do experimento foi de 84 dias: 21 para adaptação dos animais às instalações e à dieta e 63 para coleta dos dados.

Os tratamentos testados foram os mesmos do ensaio de digestibilidade, ou seja, grão de milho inteiro (GMI), grão de milho inteiro tratado com uréia (GMIU) e grão de milho moído na forma de quirera (GMM). A relação volumoso:concentrado de 40:60, na MS, a silagem de sorgo forrageiro (híbrido AG 2002) e o concentrado também foi a mesma (Tabela 1).

A alimentação dos animais foi feita em duas refeições diárias, uma pela manhã e a outra à tarde, divididas em porções iguais. As sobras dos alimentos no cocho foram retiradas e pesadas todas as manhãs para o controle e o ajuste do consumo de matéria seca. Para obtenção das amostras dos alimentos e das sobras e fezes, realizaram-se os mesmos procedimentos descritos no ensaio de digestibilidade.

A pesagem dos animais foi feita em intervalos de 21 dias, sempre precedida de jejum de sólidos e líquidos de 12 a 14 horas. Neste ensaio, os parâmetros avaliados foram o ganho de peso médio diário (GMD), o consumo voluntário da matéria seca (CMS) e a conversão alimentar (CA).

O delineamento experimental utilizado foi em blocos casualizados, com três tratamentos e cinco repetições. A blocagem foi realizada de acordo com a raça e o peso vivo inicial dos animais. Os dados de cada parâmetro avaliado foram submetidos à análise de variância e as diferenças entre as médias foram analisadas pelo teste Tukey a $5 \%$ de probabilidade (SAS, 1990).

\section{Resultados e Discussão}

A avaliação das proporções da granulometria do milho moído (PGMM) indicou que $85 \%$ dos grãos moídos ficaram retidos entre as peneiras de 3,36 a $0,71 \mathrm{~mm}$, com média de $1,69 \mathrm{~mm}$, portanto, a moagem foi classificada como grosseira. Alcalde (1997), ao moer o grão de milho grosseiramente, também observou que $86 \%$ dos grãos moídos ficaram retidos nas peneiras de 2,38 a $0,84 \mathrm{~mm}$, com média de 1,61 mm. O diâmetro geométrico médio (DGM) observado neste trabalho foi de $1.249 \mu \mathrm{m}$, com um consumo de energia elétrica de $6,3 \mathrm{kWh}$ por tonelada de grãos moídos. 
Tabela 2 - Composição química, expressa na MS, da silagem de sorgo, dos ingredientes utilizados nos concentrados e das dietas experimentais

\begin{tabular}{|c|c|c|c|c|c|c|c|c|c|c|c|}
\hline \multirow[t]{2}{*}{ Item } & \multirow[t]{2}{*}{ MS (\%) } & \multicolumn{10}{|c|}{$\% \mathrm{MS}$} \\
\hline & & $\mathrm{MM}$ & $\mathrm{PB}$ & $\mathrm{EE}$ & FDN & FDA & HEM & CEL & LIG & $\mathrm{AM}$ & EB \\
\hline Silagem sorgo & 31,3 & 4,8 & 5,2 & 3,3 & 61,8 & 37,7 & 24,1 & 26,7 & 9,1 & 11,4 & $4.182,1$ \\
\hline Farelo soja & 88,0 & 7,2 & 43,7 & 2,0 & 13,7 & 8,9 & 4,8 & 6,7 & 2,6 & 9,8 & $4.571,5$ \\
\hline Milho & 88,6 & 2,6 & 7,8 & 4,0 & 12,0 & 2,9 & 9,0 & 2,6 & 1,0 & 70,3 & $4.402,3$ \\
\hline Milho tratado com uréia & 86,8 & 6,1 & 12,5 & 4,2 & 14,3 & 3,4 & 10,9 & 2,7 & 1,7 & 63,8 & $4.284,3$ \\
\hline GMI & 65,8 & 6,0 & 14,6 & 3,3 & 32,0 & 17,8 & 13,3 & 12,9 & 4,5 & 34,8 & $4.264,8$ \\
\hline GMIU & 65,0 & 6,9 & 14,9 & 3,4 & 33,0 & 18,0 & 15,0 & 12,4 & 4,8 & 32,6 & $4.242,6$ \\
\hline GMM & 65,8 & 6,0 & 14,6 & 3,3 & 32,0 & 17,8 & 13,3 & 12,9 & 4,5 & 34,8 & $4.264,8$ \\
\hline
\end{tabular}

GMI = grão de milho inteiro; GMIU = grão de milho inteiro tratado com uréia; GMM = grão de milho moído.

Apesar de o consumo de MS ter sido 6\% menor (Tabela 3) nos animais que receberam a dieta contendo GMIU (grão de milho inteiro tratado com uréia), estatisticamente $(\mathrm{P}<0,05)$ o consumo de MS não foi influenciado pelo processamento do grão de milho, com média de $5,68 \mathrm{~kg} / \mathrm{dia}$. Esse consumo está em consonância com o recomendado pelo NRC (1996) de 5,6 kg MS/dia, para novilhos com cerca de $200 \mathrm{~kg}$ de peso vivo e ganho de peso médio diário de $1,250 \mathrm{~kg}$.

Russell et al. (1988) também não encontraram diferenças no consumo de MS ao fornecerem dietas semelhantes às deste ensaio, mas com novilhos de $465 \mathrm{~kg}$ de peso vivo, porém com relação volumoso:concentrado na dieta total de 20:80. Entretanto, Saenger et al. (1982) verificaram maior consumo de MS em bezerros (A.Angus $\times$ Charolês) com $254 \mathrm{~kg}$ de peso vivo alimentados com dieta contendo grão de milho inteiro tratado com uréia em relação à dieta contendo grão de milho moído tratado com uréia. Segundo o NRC (1996), o efeito do processamento do grão no consumo de MS pode ser menos evidente quando a energia disponível do grão inteiro não processado é alta ou quando o nível de consumo dos animais é baixo.

Quanto ao aproveitamento dos nutrientes no trato gastrintestinal dos animais, estatisticamente também não foram observados (Tabela 3 ) efeitos do processamento do grão de milho nos coeficientes de digestibilidade de todos nutrientes avaliados nem no percentual de amido nas fezes e no $\mathrm{pH}$ fecal.

Possivelmente, a semelhança nos resultados observados foi ocasionada pela habilidade dos ruminantes jovens em mastigar os grãos de milho, promovendo rompimento natural do pericarpo, película que envolve a semente, exposição dos grânulos de amido e dos demais nutrientes existentes no grão à fermentação microbiana e ação das enzimas digestivas presentes no trato gastrintestinal do animal. Esses dados corroboram as informações descritas por
Orskov (1990) sobre a maior habilidade de mastigação dos bovinos jovens com até $150 \mathrm{~kg}$ de peso vivo e que, nesses casos, portanto, vantajoso o oferecimento de grãos de milho inteiros aos animais.

Turgeon et al. (1983) também não verificaram influência do processamento do grão de milho na digestibilidade aparente da MS. No entanto, Russell et al. (1988) observaram aumento na digestibilidade in vitro da matéria seca ao incubarem in vitro grão de milho inteiro tratado com uréia em relação ao grão de milho inteiro não tratado.

Bolzan et al. (2007), ao fornecerem dietas com grão de milho inteiro, inteiro tratado com uréia ou moído para animais de pequeno porte, no caso cordeiros, também não encontraram efeito do processamento na digestibilidade de MS, EE e FDN, com exceção da dieta contendo milho tratado com uréia, que proporcionou digestibilidade da $\mathrm{PB}$ superior à obtida nos demais tratamentos.

Neste estudo, a digestibilidade média do amido foi de $86,4 \%$. Chen et al. (1994), ao fornecerem dietas contendo grãos de milho laminado ou floculado, ambos no vapor, para vacas leiteiras observaram digestibilidade do amido de 91,8 e $95,9 \%$, respectivamente. Cole et al. (1976) também verificaram valores superiores a $90 \%$ para a digestibilidade do amido do grão de milho processado em diferentes formas.

As digestibilidades de energia e fibra em detergente neutro mantiveram entre si correlação (Tabela 4) alta e positiva $(\mathrm{r}=0,77 ; \mathrm{P}>\mathrm{F}=0,0005)$ e ambas com a digestibilidade do amido de forma positiva $(\mathrm{r}=0,66 ; \mathrm{P}>\mathrm{F}=0,0030 \mathrm{e}$ $\mathrm{r}=0,53 ; \mathrm{P}>\mathrm{F}=0,0355$, respectivamente) e negativa com porcentagem de amido nas fezes $(\mathrm{r}=-0,71 ; \mathrm{P}>\mathrm{F}=0,0010 \mathrm{e}$ $\mathrm{r}=-0,62 ; \mathrm{P}>\mathrm{F}=0,0098$, respectivamente). Esse resultado indica que, quanto maior a digestibilidade do amido, maiores o aproveitamento da energia e da fibra e a inversão na porcentagem de amido nas fezes.

$\mathrm{O}$ pH das fezes não apresentou correlação (Tabela 4) significativa com a digestibilidade do amido $(\mathrm{r}=0,27$; 
Tabela 3 - Consumo de nutrientes e energia, percentual de amido nas fezes $\left(\mathrm{AM}_{\mathrm{fezes}}\right)$, expressos em porcentagem, e pH das fezes $\left(\mathrm{pH}_{\text {fezes }}\right)$

\begin{tabular}{|c|c|c|c|c|c|}
\hline Item & GMI & GMIU & GMM & Média & $\mathrm{CV}$ \\
\hline Matéria seca, $\mathrm{kg} /$ dia & $5,62 \mathrm{a}$ & $5,46 \mathrm{a}$ & $5,97 \mathrm{a}$ & 5,68 & 0,33 \\
\hline Matéria seca ${ }^{1}, \%$ & $61,92 a$ & $64,73 \mathrm{a}$ & $63,90 \mathrm{a}$ & 63,51 & 1,99 \\
\hline Extrato etéreo ${ }^{1}, \%$ & $62,21 \mathrm{a}$ & $68,72 \mathrm{a}$ & $59,29 a$ & 63,83 & 5,05 \\
\hline Fibra em detergente neutro ${ }^{1}, \%$ & $42,45 \mathrm{a}$ & $40,87 \mathrm{a}$ & $39,49 a$ & 40,94 & 5,52 \\
\hline Fibra em detergente ácido ${ }^{1}, \%$ & $45,97 \mathrm{a}$ & $42,76 \mathrm{a}$ & $37,41 \mathrm{a}$ & 42,05 & 4,45 \\
\hline Energia $^{1}, \%$ & $63,14 a$ & $65,37 \mathrm{a}$ & $61,98 \mathrm{a}$ & 63,50 & 2,71 \\
\hline AMfezes $^{1}, \%$ & $13,27 \mathrm{a}$ & $13,04 \mathrm{a}$ & $12,59 \mathrm{a}$ & 12,97 & 2,78 \\
\hline pHfezes & $7,08 \mathrm{a}$ & $7,03 \mathrm{ab}$ & $6,54 b$ & 6,88 & 0,21 \\
\hline
\end{tabular}

1 Valores expressos em porcentagem (\%).

Letras diferentes na mesma linha indicam diferenças significativas pelo teste Tukey a 5\% de probabilidade.

$\mathrm{GMI}$ = grão de milho inteiro; GMIU = grão de milho inteiro tratado com uréia; GMM = grão de milho moído.

Tabela 4 - Coeficientes de correlação linear $(r)$ e probabilidade do teste $F(P>F)$ entre o pH das fezes $\left(\mathrm{pH}_{\text {fezes }}\right)$, o coeficiente de digestibilidade do amido (CDAM), a porcentagem de amido das fezes (\%AM fezes $)$ e o coeficiente de digestibilidade da energia (CDE) em relação aos coeficientes de digestibilidade da fibra em detergente neutro (FDN) e da celulose (CEL) e o consumo de matéria seca (CMS), bem como entre eles

\begin{tabular}{|c|c|c|c|c|c|c|c|c|}
\hline Item & \multicolumn{2}{|c|}{$\mathrm{pH}_{\text {fezes }}$} & \multicolumn{2}{|c|}{ CDAM } & \multicolumn{2}{|c|}{$\% \mathrm{AM}_{\text {fezes }}$} & \multicolumn{2}{|c|}{$\mathrm{CDE}$} \\
\hline CDFDN & 0,43 & 0,0970 & 0,53 & 0,0355 & $-0,62$ & 0,0098 & 0,77 & 0,0005 \\
\hline CMS & $-0,58$ & 0,0108 & $-0,14$ & 0,5832 & 0,25 & 0,3214 & 0,08 & 0,7401 \\
\hline $\mathrm{pH}_{\text {fezes }}$ & 1,00 & 0,0000 & 0,27 & 0,2846 & $-0,45$ & 0,0058 & 0,45 & 0,0581 \\
\hline CDAM & 0,27 & 0,2846 & 1,00 & 0,0000 & $-0,89$ & 0,0001 & 0,66 & 0,0030 \\
\hline
\end{tabular}

$\mathrm{P}>\mathrm{F}=0,2846)$, todavia observou-se correlação significativa negativa com o consumo de MS e a porcentagem de amido nas fezes $(\mathrm{r}=-0,58 ; \mathrm{P}>\mathrm{F}=0,0108$ e $-0,45 ; \mathrm{P}>\mathrm{F}=0,0058$, respectivamente) e positiva com a energia digestível $(\mathrm{r}=0,45 ; \mathrm{P}>\mathrm{F}=0,0581)$. Esta correlação negativa do $\mathrm{pH}$ das fezes com o CMS pode indicar que o alto consumo das dietas e com conseqüente elevação da velocidade de passagem ruminal permitiu chegar à maior quantidade de alimento ainda com capacidade de fermentação no intestino grosso (ceco), aumentando a produção de metabólitos ácidos e reduzido o $\mathrm{pH}$ do bolo fecal. Esses resultados são coerentes com as informações descritas por Allison et al. (1977) e Yokoyama \& Johnson (1993). Turgeon et al. (1983) também encontraram correlação negativa do $\mathrm{pH}$ fecal com o consumo de MS.

Os processamentos dos grãos de milho também não influenciaram o (Tabela 5) consumo de alimentos, o ganho de peso e a eficiência de transformação do alimento em tecido corpóreo. O ganho médio diário, o consumo de matéria seca e a conversão alimentar médios foram de 1,2 kg/animal/dia;
6,6 kg MS/animal/dia e 5,4 kg de MS/kg ganho de peso, respectivamente. Segundo NRC (1996), para bovinos jovens com peso vivo de $200 \mathrm{~kg}$ e ganho de peso diário de $1,2 \mathrm{~kg}$, o consumo de matéria seca estimado é de $5,6 \mathrm{~kg} /$ dia.

Com um mesmo nível de inclusão do grão de milho inteiro ou moído, mas animais com pesos vivos médios superiores (360 kg) ao desta pesquisa, Vance et al. (1972), Alves et al. (1993), Alcalde (1997) e Bengochea et al. (2005) não observaram diferenças no ganho em peso e na conversão alimentar dos animais. Turgeon et al. (1983) também verificaram desempenho semelhante, mas com nível de concentrado de 85 a $95 \%$ e categoria com peso superior, $390 \mathrm{~kg}$, e não notaram diferença $(\mathrm{P}>0,05)$ entre o fornecimento do milho inteiro e o milho moído (diferença de $8 \%$ no ganho de peso e de 6\% no consumo de MS).

Por outro lado, Silva et al. (1998), de maneira similar à deste trabalho, também não encontraram diferenças no desempenho de novilhos com 19 meses ao ofertarem dietas contendo grãos de milho inteiro, úmido ou moído. Todavia, Silva et al. (1998) e Reed et al. (2005), ao avaliarem animais 
Tabela 5 - Peso vivo inicial (PVI), peso vivo final (PVF), consumo de matéria seca (CMS), ganho em peso médio diário (GMD) e conversão alimentar (CA) observados com o fornecimento de grão de milho inteiro (GMI), grão de milho inteiro tratado com uréia (GMIU) e grão de milho moído (GMM), com respectivas médias e coeficientes de variação (CV)

\begin{tabular}{lcccc}
\hline Parâmetro & GMI & GMIU & GMM & Média \\
\hline PVI, kg & $152,28 \mathrm{a}$ & $151,82 \mathrm{a}$ & $149,60 \mathrm{a}$ & 151,23 \\
PVF, kg & $229,00 \mathrm{a}$ & $230,38 \mathrm{a}$ & $230,63 \mathrm{a}$ & 230,00 \\
CMS, kg/dia & $6,176 \mathrm{a}$ & $6,575 \mathrm{a}$ & $7,065 \mathrm{a}$ & 6,605 \\
GMD, kg & $1,219 \mathrm{a}$ & $1,249 \mathrm{a}$ & $1,289 \mathrm{a}$ & 1,18 \\
CA & $5,13 \mathrm{a}$ & $5,27 \mathrm{a}$ & $5,64 \mathrm{a}$ & 0,398 \\
& & & 5,35 & 0,075 \\
\hline
\end{tabular}

${ }^{1}$ Letras iguais na mesma linha indicam que não houve diferenças significativas de acordo com o teste Tukey, a $5 \%$ de probabilidade.

mais pesados, observaram vantagem significativa no desempenho dos animais alimentados com grãos mais finamente processados, o que confirma novamente a teoria de Orskov (1990) de que há necessidade de moagem do grão de milho ofertado somente para bovinos mais pesados ou adultos.

\section{Conclusões}

O processamento do grão de milho não afeta a digestibilidade e o desempenho de bezerros com até $200 \mathrm{~kg}$ de peso vivo. Portanto, o fornecimento do grão de milho inteiro ou tratado com uréia a bovinos jovens pode ser uma alternativa econômica e prática.

\section{Literatura Citada}

ASSOCIATION OF OFFICIAL AGRICULTURAL CHEMISTS AOAC. Official methods of analysis. 13.ed. Washington D.C.: 1984. p.1141.

ALCALDE, C.R. Avaliação da granulometria ou hidratação do milho através da digestibilidade aparente, degradabilidade ruminal e desempenho de bovinos. Jaboticabal: Universidade Estadual Paulista, 1997. Tese Doutorado em Zootecnia Universidade Estadual Paulista, 1997. 111p.

ALLISON, M.J.; LITTLEDIKE, E.T.; JAMES, L.F. Changes in ruminal oxalate degradation rates associate with adaptation to oxalate ingestion. Journal of Animal Science, v.45, n.2, p.1173-1179, 1977.

ALVES, J.B.; BERGAMACHINE, A.F.; ISEPON, O.J. Utilização do milho com diferente grau de moagem na alimentação de bovinos da raça Guzerá em confinamento. In: REUNIÃO ANUAL DA SOCIEDADE BRASILEIRA DE ZOOTECNIA, 30., 1993, Rio de Janeiro. Anais... Rio de Janeiro: Sociedade Brasileira de Zootecnia, 1993. p.455.

ASSOCIATIONS OF OFFICIAL AGRICULTURAL CHEMISTS AOAC. Official methods of analysis. 13.ed. Washington D.C.: 1984. p.1141.

BEAUCHEMIN, K.A.; McALLISTER, T.A.; DONG, V. et al. Effects of mastication on digestion of whole cereal grains by cattle. Journal of Animal Science, v.72, n.2, p.236-246, 1994.

BENGOCHEA, W.L.; LARDY, G.P.; BAUER, M.L. et al. Effect of grain processing degree on intake, digestion, ruminal fermentation and performance characteristics of steers fed medium-concentrate growing diets. Journal of Animal Science, v.83, p.2815-2825, 2005

BOLZAN, I.T.; SANCHEZ, L.M.B.; CARVALHO, P.A. et al. Consumo e digestibilidade em ovinos alimentados com dietas contendo grão de milho moído, inteiro ou tratado com uréia, com três níveis de concentrado. Revista Ciência Rural, Santa Maria-RS, v.37, n.1, p.229-234, 2007

BOTHAST, R.J.; LANCASTER, E.B.; HESSELTINE, C.W. Ammonia kills spoilage molds in corn. Journal of Dairy Science, v.56, n.2, p.241-243, 1972.

CHEN, K.H.; HUBER, J.T.; THEURER, C.B. et al. Effect of steam flaking of corn and sorghum grains on performance of lactating cows. Journal of Dairy Science, v.77, n.4, p.1038-1043, 1994.

COLE, N.A.; JOHNSON, R.R.; OWEN, F.N. Influence of roughage level and corn processing method on the site and extend digestion by beef steers. Journal of Animal Science, v.43, n.2, p.490-496, 1976.

FERRELL, C.L. Metabolismo de la energía. In: CHURCH, D.C. (Ed.) El rumiante fisiología digestiva y nutrición. Zaragoza: Acribia, 1993. p.283-304.

GOERING, H.K.; Van SOEST, P.J. Forage fiber analysis Washington, D.C.: USDA, 1970. p.379. (Agricultural Handbook).

HARRIS, L.E. Métodos químicos e biológicos. In: HARRIS, L.E. (Ed.) Compilação de dados analíticos e biológicos para o preparo de tabelas de composição de alimentos para o uso nos trópicos da América Latina. Gainesville: University of Florida, Seção II, 1970. p.1401-5301.

KOTARSKI, S.F.; WANISKA, R.D.; THURN, K.K. Starch hydrolysis by the ruminal microflora. Journal Nutrition, v.122, n.1, p.178-190, 1992.

KOZLOSKY, G.V.; ROCHA, J.B.T.; RIBEIRO, H.M.N. et al, Comparison of acid and amyloglucosidase hydrolisys for estimation of non-structural polysaccharides in feed samples. Journal of the Science of Food and Agriculture, v.79, n. 8, p.1112-1116, 1999.

NATIONAL RESEARCH COUNCIL - NRC. Nutrient requeriments of beef cattle. Washington, D.C.: 1996. 158p.

ORSKOV, E.R. Alimentación de los rumiantes: principios e práctico. Zaragoza: 1990.115p.

ORSKOV, E.R. Starch digestion and utilization in ruminants Journal of Animal Science, v.63, n.6, p.1624-1633, 1986.

OWENS, F.N.; GOETSCH, A.L. Fermentación ruminal. In: CHURCH, D.C. (Ed.) El rumiante fisiología digestiva y nutrición. Zaragoza: Acribia, 1993. p.159-190.

POZZA, P.C.; POZZA, M.S.S.; RICHART, S. et al. Avaliação da moagem e granulometria do milho e consumo de energia no processamento em moinhos de martelos. Revista Ciência Rural, v.35, n.1, p.235-238, 2005.

REED, J.J.; BAUER, M.L.; LARDY, G.P. et al. Effect of processing on feeding value of sprouted barley and sprouted durum in growing and finishing rations for beef cattle. Production Animal Science, v.21, p.7-12, 2005.

RUSSELL, R.W.; LIN, J.M.C.; THOMAS, E.E. et al. Preservation of hight-moisture milo with urea: grain properties and animal acceptability. Journal of Animal Science, v.66, n.1, p.2131-2139, 1988.

SAENGER, P.F.; LEMENAGER, R.P.; HENDRIX, K.S. Anhydrous ammonia treatment of corn stover and its effects on digestibility, intake and performance of beef cattle. Journal of Animal Science, v.54, n.2, p.419-425, 1982. 
STATISTICAL ANALYSIS SYSTEM - SAS. User's guide. Version 6, 4.ed. Cary: 1990. v.1, 890p.

SILVA, J.M.; THIAGO, L.R.L.S.; FEIJÓ, G.L.D. et al. Efeito do processamento do grão de milho na engorda de bovinos confinados. In: REUNIÃO ANUAL DA SOCIEDADE BRASILEIRA DE ZOOTECNIA, 35., 1998, Botucatu. Anais... Botucatu: Sociedade Brasileira de Zootecnia, 1998. p.166-168.

SNIFFEN, C.J.; O'CONNOR, J.D.; Van SOEST, P.J. et al. A net carbohydrate and protein system for evaluating cattle diets. II. Carbohydrate and protein availability. Journal of Animal Science, v.70, n.11, p.3562-3577, 1992.

THEURER, C.B. Grain processing effects on starch utilization by ruminants. Journal of Animal Science, v.63, n.5, p.16491662, 1986.

TURGEON, O.A.; BRINK JR., D.R.; BRITTON, R.A. Corn particle size mixtures, roughage level and starch utilization in finishing steer diets. Journal of Animal Science, v.57, n.3, p.739-749, 1983.
Van SOEST, P.V. Nutritional ecology of the ruminant. 2.ed. New York: 1994. p.476.

VANCE, R.D.; PRESTON, R.L.; KOLOSTERMAN, E.W. et al. Utilization of whole shelled and crimped corn grain with varying proportions of corn silage by growing-finishing steers. Journal of Animal Science, v.35, n.3, p.598-605, 1972.

WALDO, D.R. Extend and partition of cereal grain starch digestion in ruminants. Journal of Animal Science, v.37, n.4, p.1062 1074, 1973.

YOKOYAMA, M.T.; JOHNSON, K.A. Microbiología del rumen y intestino. In: CHURCH, D.C. (Ed.) El rumiante fisiología digestiva y nutrición. Zaragoza: Acribia, 1993. p. $137-158$

ZANOTTO, D.L.; BELlAVER, C. Método de determinação da granulometria de ingredientes para uso em rações de suínos e aves. Concórdia: Embrapa Suínos e Aves, 1996. p.5. (Comunicado Técnico, 215). 